\title{
AGRICULTURAL EXTENSION: CRITERIA TO DETERMINE ITS VISIBILITY AND ACCOUNTABILITY IN RESOURCE POOR COMMUNITIES
}

\author{
Hlatshwayo, P. P. K. ${ }^{1}$ and Worth, S. H. ${ }^{2}$ \\ Correspondence author: P. Hlatshwayo. Email: Phendukani.Hlatshwayo@kzndard.gov.za
}

\begin{abstract}
Agricultural extension can be defined as the entire set of organisations that support and facilitate people engaged in agricultural production to solve problems and to obtain information, skills and technologies to improve their livelihoods and well-being. Extension officials should ensure that farmers are engaged and capacitated so that they can make production decisions that are not in conflict with nature, yet such decisions ensure that their well-being is improved. With 75\% of the world's poor living in rural areas, the topic of improved agriculture through agricultural extension is viewed as central to poverty reduction. There have been questions posed by stakeholders (communities, policy-makers and politicians) about the non-visibility and accountability of agricultural extension in the communities that it is supposed to help. There are however a number of factors (perceived or real) that make agricultural extension less or not visible nor accountable. Therefore, this paper investigates and proposes a theoretical framework or model to ensure that agricultural extension is visible and accountable to all stakeholders. This will in turn ensure that there are noticeable increases or improvement of the lives of the resource poor farmers and communities.
\end{abstract}

Keywords: Agricultural extension, Extension visibility, Relevance of extension, Rural livelihood

\section{INTRODUCTION}

Agricultural extension can be defined as the entire set of organisations that support people engaged in agricultural production and facilitate their efforts to solve problems, link to markets and other players in the agricultural value chain, and obtain information, skills and technologies to improve their livelihoods (Davis, 2009:1). With 75\% of the world's poor living in rural areas, the topic of improved agriculture (extension) is viewed as central to poverty reduction (Thirtle $\&$ Piesse, 2003:1960). For this reason, agricultural extension's relevance, visibility, accountability and sustainability are being questioned by the stakeholders for the communities that it is supposed to serve (Chintamanie, 1998:7). Ngomane (2010:3) indicated that extension practitioners, as visible faces of the discipline, carried the brunt of the criticism for less or nonvisibility and accountability of agricultural extension services by the public, policy-makers and politicians at all levels. They came to represent the negative face of public extension.

There has been much debate about agricultural extension globally. There have been many opinions about it being ineffective in delivering a population out of chronic poverty, being unable to mitigate and reduce the effect of environmental degradation, and a failure in

\footnotetext{
${ }^{1} \mathrm{PhD}$ student at the University of KwaZulu-Natal, Department of Agricultural Extension and Rural Resource Management, Nquthu Agricultural Office, Private Bag X 5501, Nquthu $3135 . \quad$ Email: Phendukani.Hlatshwayo@kzndard.gov.za

${ }^{2}$ Director, University of KwaZulu-Natal, Department of Agricultural Extension and Rural Resource Management, Private Bag X01, Scottsville 3209.
} 
increasing food and nutrition security, especially in developing countries. Kibett, Omunyin and Muchiri (2005:1) argued that, if applied successfully, agricultural extension should result in outcomes which include observable changes in attitudes and the adoption of new technologies, as well as an improved quality of life based on indicators such as health, education and housing.

In the South African context, Machethe (2004:1) indicated that during the period 1976 to 1994, poverty was more pervasive in rural areas, particularly in the former homelands (Bantustans). These homelands were KwaZulu (part of the current KwaZulu-Natal Province), Transkei and Ciskei (part of the current Eastern Cape Province), Venda and Lebowa (part of the current Limpopo Province), QwaQwa (part of the current Free State Province), Gazankulu and KaNgwane (part of the current Mpumalanga Province), and Bophuthatswana (part of the current North-West Province). Homeland governments were set out to provide basic extension services (Williams et al, 2008:9). Williams et al (2008:7) further stated that extension services provided in these areas were of poor quality in most instances. The ineffectiveness of services was not due to a lack of field officers, but rather to the low quality of their formal education and the lack of appropriate in-service training to meet on the job support needs. It has been observed in parts of these provinces that agricultural extension is of a poor quality in terms of qualifications, visibility, accountability and management of agricultural extension. This has resulted in agricultural extension not sufficiently and effectively promoting participatory extension approaches and methods that would lead to higher adoption rates of sustainable agricultural practises (choice of suitable planting dates and soils, judicious use of fertilizers) and empowering farmers to be self-reliant.

Since 1994, the democratic government of South Africa, through its national Department of Agriculture, Forestry and Fisheries (DAFF), embarked on an Extension Recovery Plan (ERP) in 2011 (DAFF, 2011). The main aim of the plan was to revitalise extension so that government agricultural interventions could be felt by farmers. The plan observed that extension and advisory services were a weak link militating against the full impact of government agricultural programmes. Thus, five strategic objectives of ERP became apparent, namely ensuring visibility and accountability of extension, promoting professionalism and image of extension, recruiting extension personnel, reskilling and re-orientating extension workers, and providing information and communication technology infrastructure and other resources.

Visibility and accountability of extension became an apex objective of ERP, required to be unpacked with models proposed and developed to measure the visibility and accountability of extension. The plan, however, does not clearly state or propose how visibility, accountability and the evaluation of agricultural extension should be quantified, and its effect or output measured other than providing uniforms and digital pens for project registration and visitation.

\section{CONCEPT AND ORIGINS OF AGRICULTURAL EXTENSION}

The dissemination and use of improved agricultural technology and management practices can be traced back thousands of years in different parts of the world, including China, Mesopotamia, Egypt, and even in the Americas. The origins of public or government-funded extension and advisory systems can be traced back to Ireland and the United Kingdom during the middle of the nineteenth century. During the potato famine in Ireland (1845-1851), agricultural advisors helped Irish potato farmers diversify into different food crops (Swanson \& Rajalahti, 2010). 
The term extension itself was first used to describe adult education programmes organised by Oxford and Cambridge Universities in England, starting in 1867. These educational programmes helped extend the work of universities beyond the campus and into the neighbouring communities (Swanson \& Rajalahti, 2010:1). It thus included components of technology transfer, broader rural development goals, management skills and non-formal education (Akinnagbe \& Ajayi, 2010:1). The role of extension and advisory services is to assist producers to make efficient, productive and sustainable use of their land and other agrarian resources, through the provision of information, advice, education and training (DAFF, 2014:9). Agricultural extension assists farmers to make efficient productive and sustainable use of their land and other resources. It is an educational process by which information or advice is generated, shared and used for decision making for farms and farm household livelihood development (Agricultural Services Innovation and Reform Project, 2003:1). Moreover, Worth (2006) indicated that the goal of agricultural extension has increased sustainability for the livelihood of the farmer.

The appropriate and important aim of modern agricultural extension services should be to impart key messages to farmers on each visit, with the complexity of these messages being increased in subsequent visits. Initial messages should aim at improving basic production techniques, with attention being focused on land preparation, the timeliness of operations, crop spacing, plant population sizes, the use of better seed varieties, and weeding. After the simple messages, attention shifts to more complex messages such as those relating to fertilizer use and pest control measures (Evenson \& Mwabu, 2001), as well as environment-productivity interaction (sustainability).

Brundtland Report (1987:16) defined sustainable development as when humanity has the ability to ensure that their development meets the needs of the present without jeopardising the future generations to meet their needs. Productivity, risks reduction, protection of the environment, economic viability, social acceptability, technical feasibility, and commercial feasibility should always be the centre of the message within the agricultural sector. This will entail that extension practitioners should understand principles, approaches and methodologies of sustainable development.

During the early years of extension, agricultural extension was applied in a linear approach where farmers or other recipients of extension were "forced" to take or consume technology provided to them. There were no clear methodologies to package and evaluate the outcome or impact of extension in terms of human capacity development as noted by Evenson and Mwabu (2001). These were classic examples of top-down supply-driven approaches as discussed by Amanuel (2007:11). These top-down supply-driven approaches are still practised in most parts of less developed countries, where relations between the farmers and extension workers are skewed in favour of the latter. This results in unquestioning of any information provided by the extension workers.

There have been mixed feelings from international organisations about relevancy and appropriateness of agricultural extension. The Food and Agriculture Organisation (FAO) registered concern about failure of agricultural extension worldwide, especially the World Bank funded and approved Training and Visit (T\&V) extension approach (FAO, 1999).

A large proportion of rural poor live only by agriculture, thus agricultural extension can be a very powerful tool for empowerment and support to community livelihoods by helping to 
improve farming and farm yields (Neuchâtel Group, 1999:7). To help the situation and people out of poverty appropriately, several agricultural extension concepts, approaches and methods had been developed over the past centuries.

\section{VISIBILITY OF AGRICULTURAL EXTENSION AMONGST STAKEHOLDERS}

According to Swanson and Rajalahti (2010), agricultural extension has three major goals which determine their activity (visibility). These goals include achieving food security (Umali \& Schwartz, 1994), improvement of rural livelihood, and improvement of natural resource management. There has been a heated debate both globally and in Africa, especially within poor countries, which was prompted by the lack of visible results in agricultural extension performance. Lack of genuine farmer participation not only results in inappropriate technologies being developed and disseminated, but is also a missed opportunity for empowerment of farmers. Experience shows that farmers who learn to experiment and develop innovations together with extension staff are better able to adapt to changing circumstances (Katz, Plüss \& Schidegger, 2007:18) and will result in agricultural extension being more truly visible.

\section{ACCOUNTABILITY OF AGRICULTURAL EXTENSION}

According to DAFF (2014), accountability is defined as an "obligation to demonstrate that work has been conducted in compliance with agreed rules and standards or to report fairly and accurately on performance results vis à vis mandated roles and/or plans”. In Africa, there is a long history of top-down approaches to governance featuring primarily upward accountability methods (Cohen \& Lemma, 2011:2). Thus, there has been a desire to reform the public extension into a system that is cost effective, responsive to farmers' needs, broad-based inservice delivery, accountable and with in-built sustainability mechanisms (Muyanga \& Jayne, 2006).

Agricultural extension lacks focus on farmer empowerment and development (World Bank, 1999:1). The current role of agricultural extension in most countries, including South Africa, is mixed and includes project initiation for political reasons and compiling irrelevant and unverifiable reports. In some cases, agricultural ministries use extension to achieve government goals which may or may not coincide with farmers' objectives as noted by Kibett et al (2005:1491). Kibett et al (2005:1494) further concluded that the relationship between extension and farmers must be improved if extension is to achieve the desired goals and accountability from both sides. It is especially important to increase extension's accountability to its clients. Emphasis needs to be placed on extension's capacity to mobilise and support farmers' groups and organisations with regards to access to inputs and provision of marketing advice.

This led to a skewed rather than balanced relationship between farmers and extension staff, a relationship that is in favour of the former at the expense of the latter. In such a relationship, farmers see extension staff as educated, knowledgeable and doing them a favour by advising them. Katz et al (2007:21) further indicated that farmers are usually reluctant to come forward with critical opinions, which makes collecting feedback a farce. Again, involving farmers effectively in planning would avoid this problem, as they are invited to reflect on joint decisions (accountability). This further results in one sided (top-down) conversations as farmers tend to 
withdraw their indigenous knowledge and experiences of the area. This situation is based on a traditional top-down supply-driven approach that provides little or no voice to the farmer.

Figure 1, as developed by the authors, proposes the model or process that should be used by state extension and advisory services in KwaZulu-Natal Province to improve its visibility and accountability amongst its stakeholders.

The process will begin with the local extension office (Deputy Director) allocating extension officers to wards or commodities and the budget to carry out extension work (farmers' visits). An appraisal or survey should be done and always be communicated or discussed with the extension office. Survey results should be analysed by the extension officer. Interventions should be discussed and be categorised into short term (can be done within 30 days), medium term (30 to 90 days) and long term (over 90 days).

The extension office should ensure that these interventions are presented and included into stakeholder meetings such as Integrated Development Plans (IDP) for local municipalities and traditional councils. Implementation, monitoring and evaluating progress while implementing interventions. Appraisal results should constantly be shared or discussed with stakeholders as a method of accountability to stakeholders. Closing out reports and planning for the following extension cycle should follow. To test and share interventions, extension officers should publish their results to provincial, national and international journals.

This will ensure that extension services are accountable and visible to local and other stakeholders through the work they do.

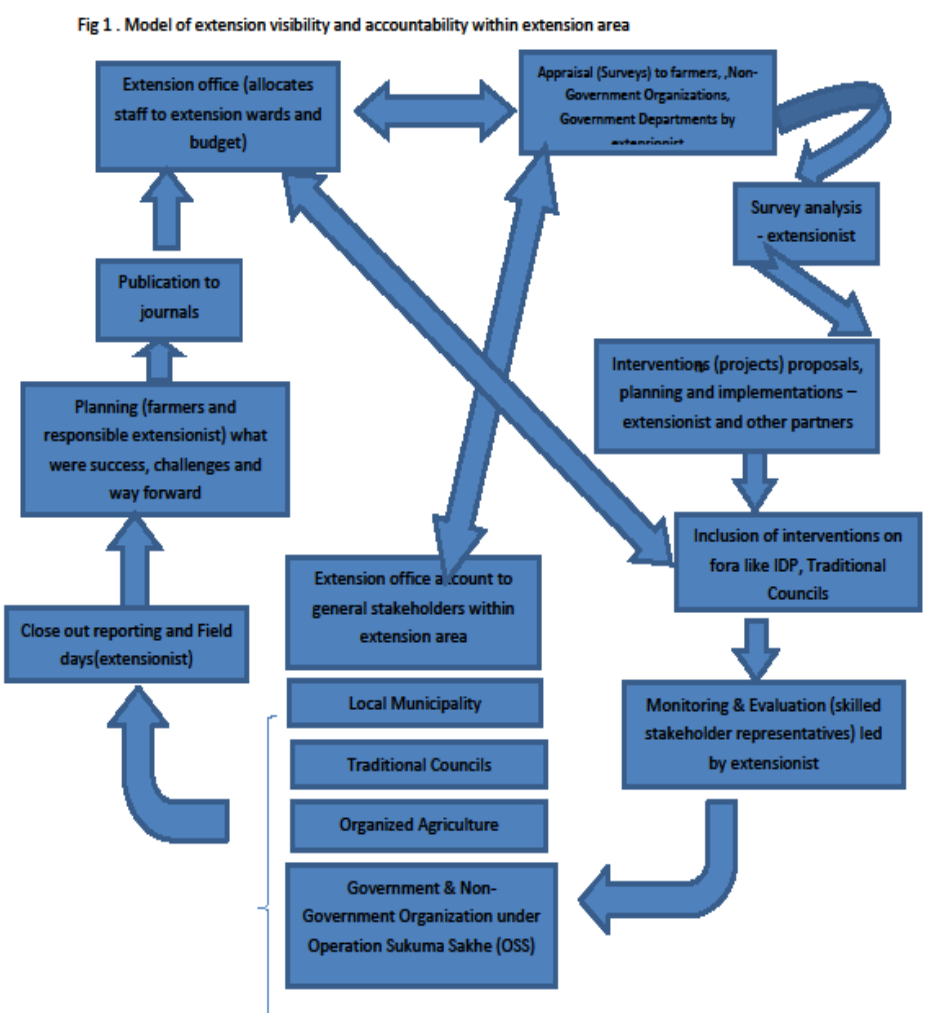

Figure 1: Model for visibility and accountability of extension to farmers and other stakeholders 


\section{RECOMMENDATIONS}

The following criteria should be used, mainly in state extension service to evaluate visibility of agricultural extension officials within a five-year cycle:

1. Famers/ Farmer organisation (primary targets) know the existence of extension service in a contact point (awareness and contact).

2. Use advice provided by extension service (use/ adoption).

3. Local leadership (village traditional leaders or Induna in the South African/ IsiZulu context), in this category a constitutional structure like Traditional Council should be used to average the answers received.

4. Other organisations involved in agriculture and rural development. This category should include sister government department (Department of Social Development, Department of Rural Development), non-governmental organisations and Institutions of Higher Learning.

5. Scientific and other agricultural/ extension publications.

Moreover, it is important that for effective accountability for extension staff and farmers, frontline extension staff at the village level (in South Africa at the ward level) should be well informed and trained at the Master's level as the basis, who would visit farmers frequently and regularly to provide relevant technical messages, and not only bring farmers' problems to the attention of researchers, but be able to solve such problems with the farmers using basic and advanced scientific investigation methods. Farmers should be empowered or empower themselves with numeric basic skills through adult basic education and college education. This will empower them to articulate and question any advice provided. Farmers should be accountable to the extension staff by committing to agreed programmes and operations.

\section{CONCLUSION}

With changes in the world and natural resources becoming scarce and competitive, it is clear that agricultural extension should adapt by making an impact on the rural poor and marginalised if it has to be continuously supported by the stakeholders. It should be responsive and directly address farmers' and stakeholders' needs. As more people become aware of their rights, strategies should be in place to empower extension practitioners so that their work in the communities and amongst stakeholders is relevant, visible and accountable. Most importantly, extension should make a positive impact on the rural poor by increasing productivity and reporting to stakeholders.

\section{REFERENCES}

AGRICULTURAL SERVICES INNOVATION AND REFORM PROJECTS (ASIRP), 2003. Agricultural extension in Bangladesh: An entitlement of all farmers. The results of a national extension coverage survey. Bangladesh.

AKINNAGBE, O.M. \& AJAYI, A.R., 2010. Challenges of farmer-led extension approaches in Nigeria. World J. Agric. Sci., 6(4):353-359.

AMANUEL, A., 2007. Farmer led innovation: Experience. An impact evaluation on experiences and challenges in Ethiopia. Agriservice Ethiopia, 1-11. 
BRUNDTLAND REPORT, 1987. Report of the World Commission on environment and development: Our common future. Oslo, Norway.

CHINTAMANIE, B., 1998. Guyana agricultural extension in a changing environment towards a farming systems approach [viewed 5 December 2015]. Available from: http://independent.academia.edu/BissasarChintamanie

COHEN, M.J. \& LEMMA, M., 2011. Agricultural extension services and gender equality: An institutional analysis of four districts in Ethiopia. IFPRI Discussion Paper No. 01094. Washington, D.C., United States of America.

DEPARTMENT OF AGRICULTURE, FORESTRY AND FISHERIES (DAFF), 2011. National framework for extension recovery plan. Pretoria, South Africa.

DEPARTMENT OF AGRICULTURE, FORESTRY AND FISHERIES (DAFF), 2014. National extension and advisory services policy. Pretoria, South Africa.

DAVIS, K.E., 2009. Agriculture and climate change: An agenda for negotiation in Copenhagen. The important role of extension systems. IFPRI., 16(11):1-2.

EVENSON, R.E. \& MWABU, G., 2001. The effects of agricultural extension on farm yields in Kenya. Afr. Dev. Rev., 13(1):1-23.

FOOD AND AGRICULTURE ORGANISATION (FAO), 1999. The Farming Systems Development (FSD) approach to improved management of farm systems - An FSD handbook for the front-line extension worker. Rome, Italy.

KATZ, E., PLÜSS, L. \& SCHEIDEGGER, U., 2007. Capitalizing experiences on the researchextension interface, forging strategic alliances for innovation: Preliminary insights from case examples, personal experiences and literature. Lindau, Germany.

KIBETT, J.K, OMUNYIN, M.E. \& MUCHIRI, J., 2005. Elements of agricultural extension policy in Kenya: Challenges and opportunities. In African Crop Science Conference Proceedings, Vol. 7, pp. 1491-1494.

MACHETHE, L., 2004. Agriculture and poverty in South Africa: Can agriculture reduce poverty? Paper presented to the Overcoming Underdevelopment Conference. Pretoria, South Africa.

MUYANGA, M. \& JAYNE, T.S., 2006. Agricultural extension in Kenya: Practice and policy lessons. Working Paper 26/2006. Egerton University, Kenya.

NEUCHÂTEL GROUP, 1999. Common framework on agricultural extension. Paris, France.

NGOMANE, T., 2010. From a deficit-based to an appreciative inquiry approach in extension programs: Constructing a case for a positive shift in the current extension intervention paradigm. JIAEE., 17(3):57-68.

SWANSON, B.E. \& RAJALAHTI, R., 2010. Strengthening agricultural and advisory system: Procedure of assessing, transforming and evaluating extension systems. Agriculture and Rural Development Discussion Paper No. 45. Washington, D.C., United States of America.

THIRTLE, C., LIN, L. \& PIESSE, J., 2003. The impact of research-led agricultural productivity growth on poverty reduction in Africa, Asia and Latin America. World Dev., 31(12):1959-1975. 
UMALI, D.L. \& SCHWARTZ, L., 1994. Public and private agricultural extension: Beyond traditional frontier. Discussion Paper No. 236. Washington, D.C., United States of America.

WILLIAMS, B., MAYSON, D., DE SATGÉ, R., EPSTEIN, S. \& SEMWAYO, T., 2008. Extension and small holder agriculture: Key issues from a review of the literature. Phuhlisani, 1-28.

WORLD BANK, 1999. Agricultural extension the Kenya Experience. Précis No. 198.

WORTH, S., 2006. Agriflection: A learning model for agricultural extension in South Africa. J Agric. Educ. Ext., 12(3):179-193. 
